\title{
PEMILIHAN PEMASOK DAN PENENTUAN KUANTITAS PESAN PAKAN TERNAK MENGGUNAKAN MULTI OBJECTIVE LINEAR PROGRAMMING
}

\author{
Sintya Ratnasari"), Stephani Diesya, Yogie Budi P., Yuniaristanto dan \\ Wahyudi Sutopo
}

Program studi Teknik Industri, Fakultas Teknik, Universitas Sebelas Maret

Jl. Ir. Sutami 36A, Surakarta 57126, Indonesia

(Received: January 8, 2018/ Accepted: November 30, 2018)

\begin{abstract}
Abstrak
Artikel ini merupakan pengembangan dari artikel Musyafak, dkk (2012) yang membahas mengenai penilaian kinerja supplier pakan ternak menggunakan Analytic Network Process(ANP) dan Rating Scale (Studi kasus PT. DMC, Malang, Jawa Timur). PT. DMC merupakan perusahaan yang bergerak dalam bidang peternakan yang memerlukan pakan ternak dari pihak ketiga. Dalam artikelnya, Musyaffak, dkk sudah melakukan penilaian kinerja dari masing-masing pemasok tetapi belum menggunakan penilaian tersebut sebagai bahan pertimbangan untuk menentukan jumlah pesanan pakan ternak yang optimal. Saat ini terdapat tiga pemasok yang bekerja sama dengan perusahaan sehingga pemilihan pemasok merupakan hal yang penting bagi departemen pembelian. Enterprise Resource Planning(ERP) sistem dalam proses pemilihan pemasok dapat menghasilkan penyimpanan biaya dan waktu. Artikel ini bertujuan untuk penentuan pemasok dan jumlah pakan ternak yang harus dipesan pada setiap pemasok dengan menggunakan Multi Objective Linear Programming. Model tersebut dikembangkan berdasarkan tiga kunci utama ERP. Fungsi Tujuan dari model untuk meminimasi biaya, defect rate, delivery delay rate dan supplier rate. Model dipecahkan dengan bantuan Microsoft Excel Solver Software. Hasil menunjukan, pesanan untuk ketiga pemasok adalah 100, 100 dan 32 tons.
\end{abstract}

Kata kunci: Analytical Network Process (ANP); Enterprise Resource System (ERP); Multi Objetive Linear Programming (MOLP), dan supplier selection

\begin{abstract}
[Title: Supplier Selection and Order Quantity Allocation using Multi Objective Linear Programming] This article is an article of development of Musyaffak, Astuti, and Effendi (2012) which discussed about the Assessment of Supplier Performance of Animal Feed Using Analytic Network Process Method (ANP) and Rating Scale (Case Study of PT DMC Malang East Java). PT. DMC is a company engaged in the field of animal husbandry that need to order animal feed. In the article, Musyaffak et al have conducted a performance assessment of each supplier but have not used the assessment as a consideration to determine the optimal number of animal feed orders. There are three suppliers that work together with the company so, the most important function of a purchasing department is supplier selection. An Enterprise Resource Planning (ERP) system in the process of supplier selection may result in great savings in cost and time. This paper aims for selection supplier and to determine the optimal feed orders for each suppliers using Multi Objective Linear Programming. The model developed based on three ERP key. The objective function of the model is to find the minimum cost, defect rate, delivery delay rate and supplier rate. The model was solved using Microsoft Excel Solver Software. As the result, third suppliers are given orders for 100, 32 and 100 tons.
\end{abstract}

Keywords: Analytical Network Process (ANP); Enterprise Resource System (ERP); Multi Objetive Linear Programming (MOLP), and supplier selection

\footnotetext{
*) Penulis Korespondensi.

E-mail: Sintyaratnasari45@gmail.com
} 


\section{Pendahuluan}

Pemasok merupakan salah satu entitas penting dalam jaringan rantai pasok. Pemasok berfungsi untuk menjamin ketersediaan bahan baku sehingga keberadaan pemasok merupakan aspek yang sangat penting bagi berjalannya perusahaan. Jumlah pemasok yang tidak sedikit membuat perusahaan harus memilih pemasok terbaik bagi perusahaannya. Perusahaan juga dihadapkan dengan adanya berbagai macam pemasok dengan kekurangan dan kelebihannya masing-masing. Pemilihan pemasok oleh perusahaan sangat berdampak pada biaya pembelian (Ghodyspour, 2001). Permasalahan pemilihan pemasok tidak hanya dilihat berdasarkan harga terendah tetapi terdapat beberapa kriteria lain seperti kualitas, kecepatan pengiriman dan lain-lain.

Penelitian ini merupakan pengembangan dari artikel (Musyaffak dkk, 2012) yang membahas mengenai Penilaian Kinerja Supplier Pakan Ternak Menggunakan Metode Analytical Network Process (ANP) dan Rating Scale (Studi kasus PT. DMC Malang Jawa Timur). Pada artikel tersebut, Musyaffak dkk sudah melakukan penentuan bobot dan penilaian kinerja dari masing masing pemasok akan tetapi, penelitian tersebut masih belum menggunakan penilaian tersebut sebagai bahan pertimbangan untuk menentukan jumlah pesanan pakan ternak yang optimal. Pada penelitian ini akan dilakukan pengembangan penelitian dengan menggabungkan tiga metode yaitu ANP, Rating Scale dan Linear programming dalam sistem ERP untuk menentukan serta mengoptimalkan kuantitas pesan pakan ternak dari pemasok yang terpilih.

ERP merupakan sistem informasi untuk merencanakan dan mengintegerasikan semua subsistem perusahaan termasuk keuangan, pembelian, produksi, sumber daya manusia dan penjualan. Fungsi utama dari ERP yaitu untuk mengintegerasikan prosedur operasi antar departemen dan sistem informasi manajemen (Yang dkk, 2007). ERP secara efektif dapat mengurangi biaya rantai pasokan, mempersingkat waktu produksi, meningkatkan kualitas produk, memberikan layanan yang lebih baik kepada pelanggan, dan menyeimbangkan perkiraan penawaran dan permintaan (Tarantilis dkk, 2008).

PT. DMC merupakan perusahaan yang bergerak dalam bidang peternakan ayam. Perusahaan ini memiliki tiga pemasok tetap yang berasal dari Jombang (Pemasok 1), Gresik (Pemasok 2) dan Pasuruan (Pemasok 3). Permasalahan yang terdapat pada perusahaan yaitu pada kinerja pemasok seperti keterlambatan pengiriman, ketidaksesuaian kuantitas serta adanya kerusakan pakan ternak. Perusahaan sudah melakukan penilaian kinerja dengan menggunakan kriteria efficiency, flexibility, responsiviness dan food quality (Aramyan dkk, 2007) dengan menggunakan metode Analytic Network Process (ANP). Metode ANP merupakan generalisasi dari AHP yang mempertimbangkan ketergantungan antara unsurunsur hirarki (Singgih, 2009).

Hasil yang didapatkan dari pengukuran kinerja belum diterapkan sebagai bahan pertimbangan untuk menentukan jumlah pesanan pakan ternak yang optimal. Sehingga proses pemesanan pakan ternak hanya didasari oleh kebiasaan yang selama ini sudah terjalin antara perusahaan dengan pemasok. Perusahaan perlu memperhitungkan jumlah pesanan optimal untuk setiap pemasok dengan menggunakan Multi Objective Linear Programming. Metode ini telah dipakai untuk menentukan jumlah dan waktu memasok, tingkat keterampilan petani, meningkatkan kualitas target serta menentukan biaya CSR (Sutopo dkk, 2012); mengembangkan model pemrograman linier multinasional dalam divisi pembelian pabrik baja berskala besar (Gao dan Tang, 2003); membentuk model pemrograman multi-tujuan dan campuran-integer untuk beberapa sumber saat memesan dalam jumlah banyak dengan diskon (Xia dan $\mathrm{Wu}, 2007$ ); Menentukan pemasok dan jumlah pesanan yang harus dipesan pada setiap pemasok (Shaw dan Thakur, 2012); Melakukan agregasi perencanaan produksi(Wang dan Liang, 2004); Mengevaluasi pemasok dan menentukan jumlah pesanan (Özgen dan Tuzkaya, 2008); Optimalisasi teknologi konversi biomassa serta optimalisasi limbah padat (Fazlollahi dan Marechal, 2013). Dari beberapa artikel terdahulu yang sudah dilakukan, dapat membuktikan bahwa Multi Objective Linear Programming dapat diterapkan dalam pemilihan pemasok dan penentuan jumlah pesanan yang optimal. Oleh karena itu, pada artikel akan dilakukan pengembangan model berbasis sistem ERP untuk menentukan jumlah pesanan optimal dengan menggunakan Multi Objective Linear Programming.

\section{Bahan dan Metode}

Penelitian ini merupakan pengembangan dari penelitian Musyaffak dkk, 2009. Penelitian dilakukan pada PT. DMC Kecamatan Jabung, Kabupaten Malang pada bulan Februari 2013 - Juli 2013. Kriteria dan subkriteria yang digunakan dalam penelitian terdahulu diadopsi dari jurnal Armayan(2007).

Analisis penentuan pemasok dan jumlah pesanan optimal dilakukan dengan mengkombinasikan ANP, Rating Scale dan Linear Programming ke dalam sistem ERP yang ada pada perusahaan. Sistem ERP ini kemudian hanya akan diterapkan pada departemen pembelian bahan baku. Hal ini dilakukan untuk mengoptimalkan pembelian bahan baku yang dibutuhkan oleh perusahaan pakan ternak. Berikut 
merupakan gambaran sistem ERP yang ada di perusahaan.

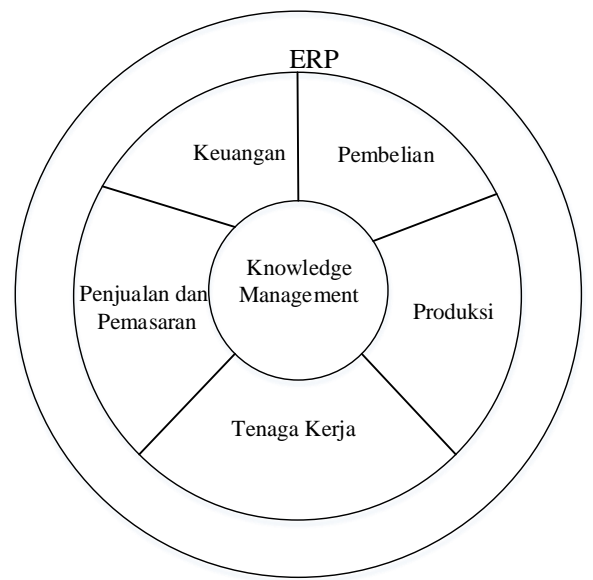

Gambar 1. Sistem ERP dalam Perusahaan

Berikut merupakan langkah-langkah yang dilakukan dalam penelitian ini :

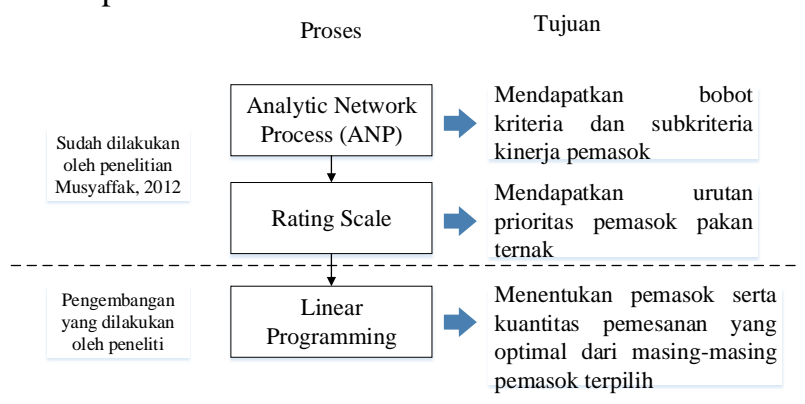

Gambar 2. Proses Pemilihan Pemasok

\section{Formulasi Model}

Model MOLP yang digunakan pada penelitian ini berdasarkan pada hasil penelitian Ceby dan Bayraktar (2003) serta Ting dan Cho (2008) yang menerapkan tiga komponen sistem ERP yang terdiri dari biaya, kualitas dan waktu.

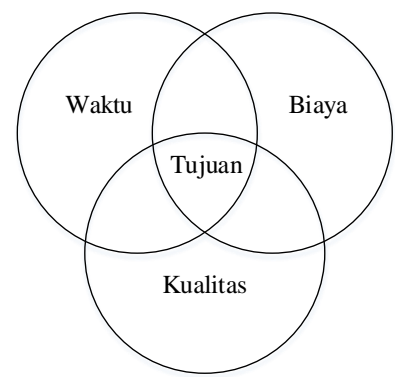

Gambar 3. Komponen Sistem ERP

Formulasi model MOLP pada artikel ini terdiri dari 4 tujuan yaitu sebagai berikut :

1. Biaya - Meminimasi biaya pesan

$$
\operatorname{Min} \mathrm{Z}_{\mathrm{i}}=\sum_{\mathrm{i}}^{\mathrm{m}} \sum_{\mathrm{j}}^{\mathrm{n}} \mathrm{c}_{\mathrm{ij}} \times \mathrm{X}_{\mathrm{ij}}
$$

2. Kualitas - Meminimasi penolakan bahan baku

$$
\text { Min } \mathrm{Z}_{2}=\sum_{\mathrm{i}}^{\mathrm{m}} \sum_{\mathrm{j}}^{\mathrm{n}} \mathrm{q}_{\mathrm{ij}} \times \mathrm{X}_{\mathrm{ij}}
$$

3. Waktu - Meminimasi keterlambatan pengiriman Min $\mathrm{Z}_{3}=\sum_{\mathrm{i}}^{\mathrm{m}} \sum_{\mathrm{j}}^{\mathrm{n}} \mathrm{d}_{\mathrm{ij}} \times \mathrm{X}_{\mathrm{ij}}$

4. Rating - Minimasi deviasi nilai kriteria rating supplier

$\operatorname{Min} \mathrm{Z}_{4}=\sum_{\mathrm{i}}^{\mathrm{m}} \sum_{\mathrm{j}}^{\mathrm{n}} \mathrm{R}_{\mathrm{ij}} \times \mathrm{X}_{\mathrm{ij}}$

Adapun yang menjadi parameter pada fungsi tujuan biaya adalah harga bahan baku, pada fungsi tujuan kualitas adalah presentase penolakan bahan baku yang dikirim, pada fungsi tujuan pengiriman adalah keterlambatan pengiriman bahan baku dan rating supplier yang didapatkan dari paper yang dijadikan acuan. Fungsi kendala pada model MOLP ini adalah:

1. Kendala kebutuhan atau demand - jumlah total pemesanan tiap jenis bahan baku kepada pemasok harus sama dengan demand yang dibutuhkan perusahaan.

$\sum_{\mathrm{j}}^{\mathrm{n}} \mathrm{X}_{\mathrm{ij}}=\forall \mathrm{D}_{\mathrm{i}}$

2. Kendala minimal pemesanan - jumlah minimal pemesanan bahan baku untuk setiap pemasok tidak boleh lebih kecil daripada kuantitas pesan minimal untuk setiap pemasok.

$$
\mathrm{X}_{\mathrm{ij}} \leq \mathrm{Q}_{\mathrm{I} \text { maks }} \forall \mathrm{i}, \mathrm{j}
$$

3. Kendala maksimal pemesanan - jumlah maksimal pemesanan bahan baku untuk setiap pemasok tidak boleh lebih besar daripada kuantitas pesan minimal untuk setiap pemasok $\mathrm{X}_{\mathrm{ij}} \geq \mathrm{Q}_{\mathrm{I}[\min } \forall \mathrm{i}, \mathrm{j}$

4. Kendala non negatif - variabel keputusan Xij bukan bilangan negatif.

$\mathrm{X}_{\mathrm{y}} \leq 0 \forall \mathrm{i}, \mathrm{j}$

Konstanta pada model MOLP:

Cij : Harga bahan baku i dari pemasok j (Rp/ton)

qij : Presentase penolakan bahan baku i dari pemasok j (\%)

: Presentase Keterlambatan pengiriman bahan baku i dari pemasok j (\%)

dij : Presentase Keterlambatan pengiriman bahan baku i dari pemasok j (\%)

Di : Jumlah kebutuhan bahan baku i (ton)

Rij : Rating pemasok dari paper sebelumnya

Qij min : Kuantitas pesan minimal bahan baku i kepada pemasok j (ton)

Qij : Kuantitas pesan maksimal bahan baku i maks kepada pemasok j (ton)

Variabel keputusan pada model MOLP

Xij : Jumlah bahan baku i yang dipesan ke pemasok $\mathrm{j}$ (ton) 


\section{Formulasi Model Pada Excel Solver}

Formulasi untuk setiap fungsi tujuan dengan menggunakan excel solver adalah sebagai berikut:

a) Fungsi tujuan pertama adalah meminimasi biaya pesan, maka model matematis fungsi tujuan ini adalah :

(Harga Pemasok 1 X Jumlah Bahan Baku yang dipesan $(\mathrm{Xij}))+($ Harga Pemasok 2 X Jumlah Bahan Baku yang dipesan $(\mathrm{Xij}))+($ Harga Pemasok 3 X Jumlah Bahan Baku yang dipesan(Xij))

b) Fungsi Tujuan kedua adalah meminimasi penolakan bahan baku, maka model matematis fungsi tujuan ini adalah:

(Quality Defect Rate Pemasok 1 X Jumlah Bahan Baku yang dipesan $(\mathrm{Xij}))+($ Quality Defect Rate Pemasok 2 X Jumlah Bahan Baku yang dipesan $(\mathrm{Xij}))+($ Quality Defect Rate Pemasok $3 \mathrm{X}$ Jumlah Bahan Baku yang dipesan(Xij))

c) Fungsi Tujuan ketiga adalah meminimasi keterlambatan pesanan, maka model matematis fungsi tujuan ini adalah:

(Delivery Rate Pemasok 1 X Jumlah Bahan Baku yang dipesan $(\mathrm{Xij}))+($ Delivery Rate Pemasok $2 \mathrm{X}$ Jumlah Bahan Baku yang dipesan $($ Xij $))+($ Delivery Rate Pemasok 3 X Jumlah Bahan Baku yang dipesan(Xij))

d) Fungsi Tujuan ketiga adalah meminimasi deviasi rating criteria supplier yang didapat dari perhitungan Rating Score, maka model matematis fungsi tujuan ini adalah :

(Rate Pemasok $1 \mathrm{X}$ Jumlah Bahan Baku yang dipesan $(\mathrm{Xij}))+($ Rate Pemasok $2 \mathrm{X}$ Jumlah Bahan Baku yang dipesan $(\mathrm{Xij}))+($ Rate Pemasok $3 \mathrm{X}$ Jumlah Bahan Baku yang dipesan(Xij))

\section{Hasil dan Pembahasan}

Pada artikel yang ditulis oleh Musyaffak, Astuti, dan Effendi (2012) telah dilakukan penilaian kinerja untuk ketiga supplier dengan menggunakan ANP dan menghasilkan bobot sebesar 4,376 untuk supplier Z, 3,621 untuk supplier $\mathrm{Y}$ dan 2,772 untuk supplier $\mathrm{X}$. Sampai dengan saat ini perusahaan telah bekerja sama dengan tiga pemasok pakan ternak yaitu supplier X, Y dan Z. Ketiga pemasok tersebut memiliki jumlah minimal order pembelian yang sama yaitu 4 ton pakan ternak per pesanan. Jumlah pesanan setiap bulan kepada masing-masing pemasok ditentukan oleh perusahaan sesuai dengan kebutuhan. Tabel 1. menunjukkan profil pemasok pakan ternak di PT. DMC.

\section{ANP}

Analytical Network Process (ANP) merupakan penilaian kinerja yang digunakan untuk memperoleh nilai bobot kinerja pemasok. Adapun hasil nilai bobot kriteria pemasok dapat dilihat pada Tabel 2.
Tabel 1. Data Pemasok

\begin{tabular}{cccc}
\hline Pemasok & Pemasok 1 & Pemasok 2 & Pemasok 3 \\
\hline Harga (Rp) & 6000 & 6500 & 5500 \\
\hline $\begin{array}{c}\text { Kebutuhan } \\
\text { ton) }\end{array}$ & 232 & 232 & 232 \\
\hline $\begin{array}{c}\text { Kapasitas } \\
\text { (ton/ bulan) }\end{array}$ & 100 & 100 & 100 \\
\hline $\begin{array}{c}\text { Kuantitas } \\
\text { Pesan } \\
\text { Minimal (ton) }\end{array}$ & 4 & 4 & 4 \\
\hline
\end{tabular}

Tabel 2. Bobot Hasil ANP

\begin{tabular}{|c|c|c|c|}
\hline Pemasok & Kriteria & Subkriteria & Bobot \\
\hline \multirow{2}{*}{ Pemasok 1} & Quality & $\begin{array}{c}\text { Qulity } \\
\text { Defect rate }\end{array}$ & 0,02 \\
\hline & Flexibility & $\begin{array}{c}\text { Delivery } \\
\text { Delay Rate }\end{array}$ & 0,05 \\
\hline \multirow{2}{*}{ Pemasok 2} & Quality & $\begin{array}{c}\text { Qulity } \\
\text { Defect rate }\end{array}$ & 0,03 \\
\hline & Flexibility & $\begin{array}{c}\text { Delivery } \\
\text { Delay Rate }\end{array}$ & 0,08 \\
\hline \multirow{2}{*}{ Pemasok 3} & Quality & $\begin{array}{c}\text { Qulity } \\
\text { Defect rate }\end{array}$ & 0,02 \\
\hline & Flexibility & $\begin{array}{c}\text { Delivery } \\
\text { Delay Rate }\end{array}$ & 0,03 \\
\hline
\end{tabular}

Kriteria utama pada perusahaan pakan ternak adalah kriteria Quality dan Flexibility. Hal ini dikarenakan apabila kualitas buruk, maka akan mempengaruhi pertumbuhan ternak. Selain itu, kriteria Flexibility juga memiliki peran penting dalam menentukan waktu pemesanan.

\section{Rating Scale}

Rating Scale digunakan untuk memperoleh urutan atau prioritas dari masing-masing pemasok pakan ternak. Skala penilaian yang digunakan yaitu 1-5. Adapun hasil nilai bobot rating scale pemasok adalah sebagai berikut :

Tabel 3. Hasil penilaian Rating Scale

\begin{tabular}{cc}
\hline Pemasok & Hasil Penilaian Kinerja \\
\hline Pemasok 1 & 2,772 \\
Pemasok 2 & 3,621 \\
Pemasok 3 & 4,376 \\
\hline
\end{tabular}

Berdasarkan rating scale tersebut maka prioritas pemasok yang dipilih oleh perusahaan adalah pemasok 3 , pemasok 2, dan pemasok 1 yang didasarkan pada besarnya nilai kinerja. Dengan menggunakan pendekatan ERP, data penilaian kinerja yang diambil hanya merupakan data yang terkait biaya atau harga, pengiriman, dan kualitas produk. Persamaan model di 
atas kemudian akan diselesaikan seperti menyelesaikan permasalahan single objective linear programming yaitu satu per satu secara terpisah dengan menerapkan aturan minimax dan diselesaikan dengan menggunakan software microsoft excel solver sehingga diperoleh hasil seperti pada Tabel 4.

Tabel 4. Hasil Perhitungan SOLP

\begin{tabular}{ccccccc}
\hline $\begin{array}{c}\text { Fungsi } \\
\text { Tujuan }\end{array}$ & $\mathbf{1}$ & $\mathbf{2}$ & $\mathbf{3}$ & $\mathbf{4}$ & $\begin{array}{c}\text { Nilai } \\
\mathbf{M i n} \\
\mathbf{Z}\end{array}$ & $\begin{array}{c}\text { Nilai } \\
\mathbf{M a x} \\
\mathbf{Z}\end{array}$ \\
\hline $\mathrm{Z} 1$ & 14260 & 64800 & 12720 & 13580 & 64800 & 14260 \\
& 00 & 0 & 00 & 00 & 0 & 00 \\
\hline $\mathrm{Z} 2$ & 5,64 & 2,2 & 5,08 & 4,96 & 2,2 & 5,64 \\
\hline $\mathrm{Z} 3$ & 13,96 & 5,44 & 13,12 & 10,56 & 5,44 & 13,96 \\
\hline \multirow{2}{*}{$\mathrm{Z} 4$} & 324.9 & - & - & 376.2 & - & 376.27 \\
& 32 & 201.1 & 452.8 & 72 & 452.8 & 2 \\
\hline
\end{tabular}

Dengan bantuan software microsoft excel solver diperoleh solusi optimal dengan nilai $\mathrm{Z1}=1426000, \mathrm{Z2}$ $=5,64, \mathrm{Z3}=13,96$ dan $\mathrm{Z4}=376,272$. Sedangkan rekapitulasi hasil variabel keputusan $\mathrm{Xij}$ dapat dilihat pada Tabel 5.

Tabel 5. Hasil Rekapitulasi xij

\begin{tabular}{cc}
\hline Pemasok & $\begin{array}{c}\text { Jumlah Bahan Baku } \\
\text { yang Dipesan (xij) }\end{array}$ \\
\hline Pemasok 1 & 100 \\
\hline Pemasok 2 & 32 \\
\hline Pemasok 3 & 100 \\
\hline
\end{tabular}

Penentuan kuantitas pesanan optimal menghasilkan keputusan strategis. Dengan dilakukannya pengoptimalisasian kuantitas pesan dapat meminimasi biaya, menjamin kualitas, serta menjamin keberlangsungan perusahaan. Dalam artikel ini, proses penentuan pemasok dan penentuan kuantitas bahan baku menggunakan kombinasi antara metode Analytic Network Process (ANP), ERP dan model multi objective linear programming (MOLP). ANP digunakan untuk menentukan bobot kriteria pemilihan pemasok, sedangkan ERP digunakan untuk mengembangkan model dan MOLP digunakan untuk menentukan kuantitas pemesanannya. Model MOLP digunakan karena dalam proses pemilihan pemasok melibatkan lebih dari satu tujuan. Keempat fungsi tujuan pada penelitian ini didasarkan pada konsep ERP dan kriteria hasil ANP serta Rating scale. Hasilnya dapat dilihat pada Tabel 5. Hal ini tentunya dapat memberikan masukan kepada perusahaan untuk menentukan kuantitas pemesanan optimal yang didukung oleh keputusan harga, kualitas dan waktu pengiriman.

\section{Kesimpulan}

Dalam lingkungan ERP, biaya, waktu, dan kualitas adalah tiga kunci elemen untuk keberhasilan perusahaan. Dalam konsep push and pull, lingkungan yang kompetitif memaksa perusahaan untuk mengadopsi efisiensi cara, sistem ERP, untuk integrasi, fleksibilitas, dan operasi. Biaya material, kualitas dan waktu pengiriman dikendalikan oleh pembeli atau perusahaan dari divisi pembelian. Penghematan biaya untuk pakan dapat menyebabkan earning per share (EPS) yang lebih tinggi; kualitas tingkat yang lebih tinggi dari bahan dapat meningkatkan kepuasan pelanggan, menyebabkan mereka menjadi pelanggan berulang; pengiriman tepat waktu dapat mengurangi produksi kehilangan dan membantu pelanggan menerima kiriman mereka tepat waktu. Dalam artikel ini, tiga pemasok pakan ternak diberikan sebagai alternatif pilihan. Melalui sistem ERP, kami menemukan bahwa pemasok 1 dan 3 merupakan pemasok yang memperoleh sebagian besar jumlah pesanan dan pemasok 2 memperoleh pesanan yang paling sedikit.

\section{Saran}

Artikel ini hanya memperhitungkan jumlah pesanan optimal dengan menggunakan linear programming. Proses pemilihan supplier baru pemasok, sedangkan dalam artikel selanjutnya dapat dikembangkan lagi konsep ERP yang lebih luas.

\section{Daftar Pustaka}

Aramyan, L.H., Lansink, A G.J.M.O., Vorst, J.G.A.J. van der., dan Kooten, O. van. 2007. Perfomance. Measurement in Agri-Food Supply Chain: A Case Study. An International Journal, 12(4), 304-315.

Ceby, F. and Bayraktar, D. 2003. An Integerated approach for supplier selection. Journal of Logistics Information Management.16, 395-400.

Fazlollahi, S., Marechal, F. 2013. Multi-objective, multi-period optimization of biomass conversion technologies using evolutionary algorithms and mixed integer linear programming (MILP). Applied Thermal Engineering, 50(2), 1504-1513.

Gao, Z., \& Tang, L. (2003). A multi-objective model for purchasing of bulk raw materials of a large-scale integrated steel plant. International Journal of Production Economics, 83(3), 25-334.

Ghodsypour, S.H., O'Brien, C. 2001. The total cost of logistics in supplier selection, under condition of multiple sourcing, multiple criteria and capacity constraint. Internal journal of Production Economics, 73(!), 15-27.

Musyaffak, H., Astuti, R., Effendi, M. 2013. Penilaian Kinerja Supplier Pakan Ternak Menggunakan Metode Analytic Network Process (ANP) dan Rating Scale (Studi Kasus PT. DMC Malang, 
Jawa Timur). Jurnal Industri Kinerja Supplier Pakan ,2(3), 153-160.

Özgen, D., Tuzkaya, G. 2008. A Two-Phase Possibilistic Linear Programming Methodology for Multi-Objective Supplier Evaluation and Order Allocation Problems. Information Sciences, 178(2), 485-500

Singgih, M.L. 2009. Pemilihan Alternatif Perbaikan Kinerja Lingkungan Sektor Industri Potensial di Jawa Timur degan Metode Economic InputOutput Life Cycle Assesment (EOI-LCA) dan Analytic Network Process (ANP). Seminar Nasional Perencanaan Wilayah dan Kota ITS, Surabaya ISBN No. 978-979-98808-2-6, 106.

Shaw, K., Thakur, L.S. 2012. Supplier Selection Using Fuzzy AHP and Fuzzy Multi-Objective Linear Programming for Developing Low Carbon Supply Chain. Expert Systems with Applications, 39(9), 8182-8192.
Sutopo, W., Hisjam, M., Yuniaristanto. 2012. An AgriFood Supply Chain Model to Enhance the Business Skills of Small-Scale Farmers Using Corporate Social Responsibility. Makara Journal of Technology, 16(1), 43-50.

Tarantilis, C.D., Kiranoudis, C.T., Theodorakopoulos, N.D. 2008. A Web Based ERP System for Business Services and Supply Chain Management Aplication to Real World Process Scheduling. European Journal of Operation Research, 187(3), 310-1326.

Wang, R.C., Liang, T.F. 2004. Application of Fuzzy Multi-Objective Linear Programming to Aggregate Production Planning. Computers \& Industrial Engineering, 46(1), 17-41.

Xia, W., \& Wu, Z. (2007). Supplier selection with multiple-criteria in volume discount environment. Omega, 35(5), 494-504.

Yang, J. B., Wu, C. T., \& Tsai, C. H. (2007). Selection of an ERP system for a construction firm in Taiwan: A case study. Automation In Construction, 16(6), 787-796. 